\title{
Larvicidal Activity and Molecular Docking Studies of Vitexicarpin from Vitex negundo Linn
}

\author{
Sandhya Krishnamoorthy ${ }^{1}$, Sivakumar Muthusamy ${ }^{2, *}$, Vijayakumar Arumugam Ramamurthy ${ }^{3}$ \\ ${ }^{1}$ Faculty of Pharmacy, Sri Ramachandra Institute of Higher Education and Research, Porur, Chennai, Tamil Nadu, INDIA. \\ ${ }^{2}$ Department of Pharmacognosy, Faculty of Pharmacy, Sree Balaji Medical College and Hospital Campus, Bharath Institute of Higher Education and Research, \\ Chromepet, Chennai, Tamil Nadu, INDIA. \\ ${ }^{3}$ Department of Pharmacology, Faculty of Pharmacy, Sree Balaji Medical College and Hospital Campus, Bharath Institute of Higher Education and Research, \\ Chromepet, Chennai, Tamilnadu, INDIA.
}

\begin{abstract}
Objectives: To study the larvicidal effect of Vitex negundo Linn against mosquito larvae by larvicidal bioassay and in silico molecular docking studies. Methods: The larvicidal bioassay of Vitex negundo Linn was assessed by using WHO standard protocol and an in silico molecular docking study was performed by using Molegro Virtual Docker against Culex quinquifasciatus. The early third instar larvae of Aedes aegypti, Aedes albopictus and Culex quinquefasciatus were exposed to the extract concentrations in three replicates and different temephos concentration were taken as positive control and solvent control was also used. Results: The study results shows that of Vitex negundo Linn possess the potential larvicidal activity against third instar larvae of Culex quinquifasciatus when compared to Aedes aegypti $\mathrm{L}$ and Aedes albopictus. Percentage mortality and half-maximal effective concentration $\left(\mathrm{EC}_{50}\right)$ value were calculated against the above mentioned three species like wise Culex quinquifasciatus (83.77 ppm), Aedes aegypti (341.7 ppm), and Aedes albopictus (487.9 ppm). The highest larval mortality was found against Culex quinquifasciatus of $100 \%$ at 500 parts per million. In silico molecular docking studies using Molegro Virtual Docker against Odorant binding protein (PDB: $2 \mathrm{~L} 2 \mathrm{C}$ ) of
\end{abstract}

Culex quinquifasciatus was performed as it showed better results in in vitro study. The results reveal that phytoconstituent like Vitexicarpin showed good docking scores against the Odorant Binding Protein $2 \mathrm{~L} 2 \mathrm{C}$ and the moldock score of Vitexicarpin was found to be -87.3733 , whereas moldock score of standard Azadirachtin was found to be -110.77 . Conclusion: The present study reveal that the Vitex negundo Linn possess the potential larvicidal activity against the Culex quinquifasciatus species.

Key words: Vitex negundo Linn, Aedes aegypti L, Culex quinquefasciatus, Aedes albopictus, Molegro Virtual Docker 6.0, Odorant binding Protein, Larvicidal.

\section{Correspondence}

Dr. M Sivakumar,

Professor, Department of Pharmacognosy, Faculty of Pharmacy, Sree Balaji Medical College and Hospital Campus, Bharath Institute of Higher Education and Research, Chromepet, Chennai-600044, Tamil Nadu, INDIA.

Email id: sivampharma@gmail.com

DOI: 10.5530/jyp.2021.13.46

\section{INTRODUCTION}

Mosquito is a small, midge-like fly that belong to the family of Culicidae. Female in most species are ectoparasites, whose tube-like mouthpart pierces skin of the host to consume the blood. The human blood is rich in proteins, amino acids and other nutrients, which makes it the perfect prenatal supplement for growing the mosquito eggs that is a reason female mosquito sucking the blood. The passing from host to host, some of the transmit are extremely harmful infections such as malaria, yellow fever, chikungunya, west nile virus, dengue fever, filariasis, zikavirus, Japanese encephalitis, schistosomiasis and other arboviruses. ${ }^{1}$ The mosquito undergoes four stages of life cycle mainly in egg, larva, pupa, and adult. Approximately, it takes a month to complete its life cycle. ${ }^{2,3}$ There are approximately 3,500 species of mosquitoes in the World and 41 different types of genera, however the majority of mosquitoes fall under three genera categories: Aedes, Anopheles and Culex. Aedes causes yellow fever, dengue, malaria and encephalitis. Larvae of Aedes are larger when compared to others within 7 to 10 days, larvae of Aedes enter the pupa stage. Culex causes filariasis, malaria, encephalitis and dengue. Larvae of Culex species are present upside down because their respiratory tract is present near the tail. The third instar larvae of three species of Aedes aegypti, Aedes albopictus and Culex quinquefasciatus are used in this experiment. The mosquito larvae for this research work were obtained and authenticated from Dr. Daniel Reegan, Entomologist, Entomology Research Institute, Loyola College, and Chennai. In commercially several synthetic mosquito control repellents available in the market. All repellents have protected from mosquito bite for several hours and must be applied to all exposed skin areas. The available of common synthetic mosquito repellents is $\mathrm{N}, \mathrm{N}$-diethyl-3-methylbenzamide, commonly known as DEET, Picaridin, Permethrin, N, N -diethyl-2-phenyl-acetamide (DEPA), ethyl anthranilate (EA) and Ethyl butyl acetyl amino propionate (IR3535). The side effects like rash, skin eruptions, urticaria and respiratory problem have been encountered on the use of this type of synthetic repellents. The natural mosquito repellents like Citronella, Oil of lemon eucalyptus (OLE), Neem, Peppermint, methyl jasmonate and Lemon grass does not causes any type of skin irritation and allergic reactions as synthetic repellents and this natural type repellents are safe compared to already available synthetic one.

Vitex negundo Linn, generally known as the Chinese chaste tree, five-leaved chaste tree, or horse shoe Vitex or Monk's pepper. ${ }^{4}$ Vitex negundo Linn belongs to the family of Verbenaceae. Vitex negundo is a large aromatic shrub and with quadrangular, densely whitish, and tomentose branchlets fututre. It is an erect shrub or small tree growing height approximately 2 to 8 meterst..$^{5-9}$ The leaves are known to possess various flavonoids-chryso-splenol and vitexin, vitexicarpin, Luteolin, and Vitexin rhamnoside. Lignans, sequiterpenes, flavone glycosides, iridoid glycosides, eurotoside aucubin, stilbenes have been isolated. Chasteberry is evidence that to contain a progesterone-like compounds, vitamin-C and carotene. It contains four phenolic compounds such as salviaplebeiaside, chrysosplenol-D, isovitexin and $\gamma$-tocopherol, along 
with $\beta$-sitosterol and $\alpha$-tocoquinone. ${ }^{10-17}$ Leaves of this plant have been used as anti-bacterial, anti-tumour, astringent, acne, eczema, antipyretic, sedative, treatment of liver disorder, vermifuge, anti-parasitical, insect repellent, anti- inflammatory, catarrhal fever, remedy for cough, anti-ulcer, to treat skin disease, hair tonic to promote hair growth. ${ }^{18-23}$

\section{MATERIALS AND METHODS}

\section{In vitro studies of Vitex negundo Linn Preparation of Leaves Extract}

The leaves of Vitex negundo Linn were collected from local area, cleansed and shade dried for a week, milled and defatted using petroleum ether and macerated using ethyl acetate for $72 \mathrm{hrs}$. The extract was filtered and the filtrate was subjected to rotatory evaporator. The residue was collected and stored in the desiccator for further studies.

\section{Larvicidal Bio-Assay Procedure}

Larvicidal activities of the ethyl acetate extract of Vitex negundo Linn was assessed by using protocol of World Health Organization (WHO) (2005). ${ }^{23}$ The early third instar larvae of Aedes aegypti, Aedes albopictus and Culex quinquefasciatus were exposed to the extract concentrations in three replicates such as $31.25,62.5,125,250$ and $500 \mathrm{ppm}$. Temephos of concentration 2.5, 5.0, 7.5 and $10.0 \mathrm{ppm}$ were taken as positive control. Solvent control was also used. The extract with10 larvae were introduced using half sealed pipette and mortality of the larvae was calculated after 24hrs. Larvae were considered dead, when it sinks at the bottom where it seems to be immobilized or it completely look pitch dark. Thus the same experiment was repeated for three species and percentage mortality was calculated by using following formula to all the three species.

\section{Percentage Mortality $=$ (Number of dead larvae) Number of larvae introduced $)^{\star} 100$}

An in silico molecular docking study using Molegro Virtual Docker 2013 (ver. 6.0) software against Culex quinquifasciatus was performed and it showed better results in in vitro study.

\section{Molecular docking studies Preparation of Ligand}

The three dimension (3D) structures of the active constituents of Vitex negundo Linn which possess larvicidal property (Vitexicarpin, Luteolin, Vitexin and Vitexin rhamnoside) and standard drug (Azadirachtin $\mathrm{H})^{24}$ were retrieved either from PubChem chemical databases or drawn using Chem Sketch software ${ }^{25}$ and it has saved in a .mol format file. The study ligand has imported to the workspace and preparation of the ligand was done.

\section{Preparation of Enzyme}

The target for docking study is selected as Odorant Binding Protein. ${ }^{26-32}$ The analysis of docking study was done by initially selecting the target for the disease and followed by obtaining the three dimensional structure of Odorant Binding Protein (PDB ID: 2L2C) from protein data bank in .pdb file format. ${ }^{33}$ In docking studies the search space of the simulation was exploited and subset region of 25.0 Angstroms around the active side cleft. The water molecules has taken to consideration and replaceable by score of 0.50 .

\section{Molecular Docking Study of Molegro Virtual Docker (MVD) docking search algorithms and scoring functions}

Molegro Virtual Docker (version 6.0) is a fast and flexible protein ligand docking simulation program and it allows carrying out docking simulation in a fully integrated computational study. The MolDock software is a new empirical search algorithm and it combines differential evolution with a cavity prediction algorithm. ${ }^{34} \mathrm{MolDock}$ has an interactive optimization technique inspired by Darwinian Evolution Theory. The generate by new solution by recombination and mutation. Piecewise linear potential (PLP) is scoring function of MolDock, which is a simplified potential to whose parameters has fit to protein-ligand structures and a binding data scoring function. ${ }^{35,36}$ It has further extended in Generic Evolutionary Method for molecule DOCK (GEMDOCK) with a new hydrogen bonding term and charge schemes. ${ }^{37}$

\section{MolDock Optimizer - Parameter for docking search algorithms}

In Molegro Virtual Docker, selected parameters were used for the guided differential evolution algorithm: number of runs $=5$ (by checking constrain poses to cavity option), population size $=50$, maximum interactions $=2000$, cross over rate $=0.9$, and scaling factor $=0.5$. A0, variancebased termination scheme was selected rather than root mean square deviation (RMSD). To ensure the most suitable binding mode in the binding cavity, pose clustering was employed, which may lead to multiple binding modes.

\section{RESULTS}

From Table 1, the result has founded that Culex quinquefasciatus have higher percentage mortality rate when compared to the other two species like Aedes aegypti and Aedes albopictus and graph was plotted against percentage (\%) mortality versus log concentration. Temephos used as standard and it showed $100 \%$ mortality at $10 \mathrm{ppm}$ to all study species namely Culex quinquefasciatus, Aedes aegypti and Aedes albopictus and the results was showed in Table 2. Half-maximal effective concentration $\left(\mathrm{EC}_{50}\right)$ value for three species was determined using Graph Pad Prism (version 5.02).

The calculate half maximal effective dose concentration value of the crude extract against Culex quinquefasciatus was found to be $83.77 \mathrm{ppm}$ (41.85-167.7 ppm), $\mathrm{EC}_{50}$ value of the crude extract gainst Aedes aegypti was found to be $341.7 \mathrm{ppm}(209.8-556.6 \mathrm{ppm})$ and $\mathrm{EC}_{50}$ value of the crude extract against Aedes albopictus was found to be 487.9 ppm (319.5745.1ppm) by using the Graph Pad Prism.

An ability of the Vitex negundo contain phytoconstituents to bind with the targets has given in terms of the MolDock Score study. MolDock Score used as a parameter for analysing to the docking results. The plant contain phytoconstituents are ranked according to their binding capability of MolDock score. The ligand possessing the highest molecular docking score shows a strong affinity towards its target protein (Table 3).

In silico docking analysis of phytoconstituents from Vitex negundo Linn on Odorant binding protein (PDB ID: 2L2C) which has ranking based on MolDock score, Rerank score and H-Bond is represented in Table 3. In Figure 1, eleven corresponds to the docking pose evaluated and captured by the ligand energy inspector tool in the Molegro virtual docker. The descriptor calculation for the ligands are represented in separate excel file. Moreover, the molecular docking results effective response was found more in Vitexicarpin (Figure 2), Luteolin (Figure 3), Vitexin (Figure 4) and Vitexin rhamnoside (Figure 5), which are present in the leaves of Vitex negundo Linn.

\section{DISCUSSION}

Vector borne diseases are rapidly increasing due to chloroquine and insecticidal resistance. Synthetic mosquito repellents may trigger undesirable hazardous interaction and leads to harmful effects in human. There are no vaccines or other specific treatments for arbovirus 
Table 1: Larvicidal activity using ethyl actetae extract of V. negundo Linn against Culex quinquifasciatus, Aedes aegypti and Aedes albopictus.

\begin{tabular}{|c|c|c|c|c|c|c|c|c|c|c|}
\hline \multicolumn{10}{|c|}{ Ethyl acetate extract of Vitex negundo Linn } & \multirow{3}{*}{$\begin{array}{c}\begin{array}{c}\text { Solvent } \\
\text { control }\end{array} \\
\% \text { of } \\
\text { Mortality }\end{array}$} \\
\hline \multicolumn{2}{|c|}{31.25 ppm } & \multicolumn{2}{|c|}{$62.5 \mathrm{ppm}$} & \multicolumn{2}{|c|}{125 ppm } & \multicolumn{2}{|c|}{$250 \mathrm{ppm}$} & \multicolumn{2}{|c|}{500 ppm } & \\
\hline $\begin{array}{c}\text { No of } \\
\text { larvae } \\
\text { dead }\end{array}$ & $\begin{array}{c}\% \text { of } \\
\text { Mortality }\end{array}$ & $\begin{array}{c}\text { No of } \\
\text { larvae } \\
\text { dead }\end{array}$ & $\begin{array}{c}\% \text { of } \\
\text { Mortality }\end{array}$ & $\begin{array}{c}\text { No of } \\
\text { larvae } \\
\text { dead }\end{array}$ & $\begin{array}{c}\% \text { of } \\
\text { Mortality }\end{array}$ & $\begin{array}{c}\text { No of } \\
\text { larvae } \\
\text { dead }\end{array}$ & $\begin{array}{c}\% \text { of } \\
\text { Mortality }\end{array}$ & $\begin{array}{c}\text { No of } \\
\text { larvae } \\
\text { dead }\end{array}$ & $\begin{array}{c}\% \text { of } \\
\text { Mortality }\end{array}$ & \\
\hline \multicolumn{11}{|c|}{ Culex quinquifasciatus } \\
\hline 2 & 20 & 4 & 40 & 5 & 50 & 8 & 80 & 10 & 100 & 10 \\
\hline 1 & 10 & 3 & 30 & 7 & 70 & 8 & 80 & 10 & 100 & 0 \\
\hline 1 & 10 & 4 & 40 & 7 & 70 & 9 & 90 & 10 & 100 & 0 \\
\hline \multicolumn{11}{|c|}{ Aedes aegypti } \\
\hline 1 & 10 & 1 & 10 & 2 & 20 & 5 & 50 & 6 & 60 & 0 \\
\hline 0 & 0 & 0 & 0 & 1 & 10 & 4 & 40 & 7 & 70 & 0 \\
\hline 0 & 0 & 1 & 10 & 3 & 30 & 5 & 50 & 7 & 70 & 10 \\
\hline \multicolumn{11}{|c|}{ Aedes albopictus } \\
\hline 0 & 0 & 0 & 0 & 2 & 20 & 4 & 40 & 6 & 60 & 0 \\
\hline 0 & 0 & 1 & 10 & 2 & 20 & 4 & 40 & 5 & 50 & 0 \\
\hline 0 & 0 & 0 & 0 & 1 & 10 & 3 & 30 & 4 & 40 & 0 \\
\hline
\end{tabular}

Table 2: Larvicidal activity of positive control (Temephos) against different mosquito larvae.

\begin{tabular}{cccccc}
\hline \multirow{2}{*}{ Mosquito species } & \multirow{2}{*}{ Treatment } & \multicolumn{4}{c}{ Mortality (\%) } \\
\cline { 3 - 5 } & & $\mathbf{1 . 0} \mathbf{~ p p m}$ & $\mathbf{2 . 5} \mathbf{~ p p m}$ & $\mathbf{5 . 0} \mathbf{~ p p m}$ & $\mathbf{1 0 ~ p p m}$ \\
\hline Culex quinquifasciatus & & 99 & 100 & 100 & 100 \\
Aedes aegypti & Temephos & 79 & 98 & 100 & 100 \\
Aedes albopictus & & 68 & 96 & 99 & 100 \\
\hline
\end{tabular}

Table 3: In-silico docking analysis of phytoconstituents from Vitex negundo Linn on Odorant Binding Protein (PDB ID: 2L2C) ranking based on MolDock Score, Rerank Score and H Bond energy.

\begin{tabular}{|c|c|c|c|c|}
\hline \multicolumn{5}{|c|}{ Ranking based on MolDock Score } \\
\hline Name & Ligand & MolDock Score & Rerank Score & HBond \\
\hline [00]Azadirachtin $\mathrm{H}$ & Azadirachtin $\mathrm{H}$ & -110.77 & -81.3716 & 0 \\
\hline$[00]$ Vitexicarpin & Vitexicarpin & -87.3733 & -81.9938 & -2.5 \\
\hline [00]Luteolin & Luteolin & -85.2923 & -78.947 & 0 \\
\hline$[00]$ Vitexin & Vitexin & -76.2769 & -63.8822 & -5.72432 \\
\hline [00]Vitexin rhamnoside & Vitexin rhamnoside & -69.9377 & -68.3276 & -7.65766 \\
\hline \multicolumn{5}{|c|}{ Ranking based on Rerank Score } \\
\hline [00]Vitexicarpin & Vitexicarpin & -87.3733 & -81.9938 & -2.5 \\
\hline [00]Azadirachtin $\mathrm{H}$ & Azadirachtin $\mathrm{H}$ & -110.77 & -81.3716 & 0 \\
\hline [00]Luteolin & Luteolin & -85.2923 & -78.947 & 0 \\
\hline [00]Vitexin rhamnoside & Vitexin rhamnoside & -69.9377 & -68.3276 & -7.65766 \\
\hline [00]Vitexin & Vitexin 2 & -76.2769 & -63.8822 & -5.72432 \\
\hline \multicolumn{5}{|c|}{ Ranking based on $\mathrm{H}$ Bond energy } \\
\hline [00]Vitexin rhamnoside & Vitexin rhamnoside & -69.9377 & -68.3276 & -7.65766 \\
\hline [00]Vitexin & Vitexin & -76.2769 & -63.8822 & -5.72432 \\
\hline [00]Vitexicarpin & Vitexicarpin & -87.3733 & -81.9938 & -2.5 \\
\hline [00]Luteolin & Luteolin & -85.2923 & -78.947 & 0 \\
\hline [00]Azadirachtin $\mathrm{H}$ & Azadirachtin $\mathrm{H}$ & -110.77 & -81.3716 & 0 \\
\hline
\end{tabular}




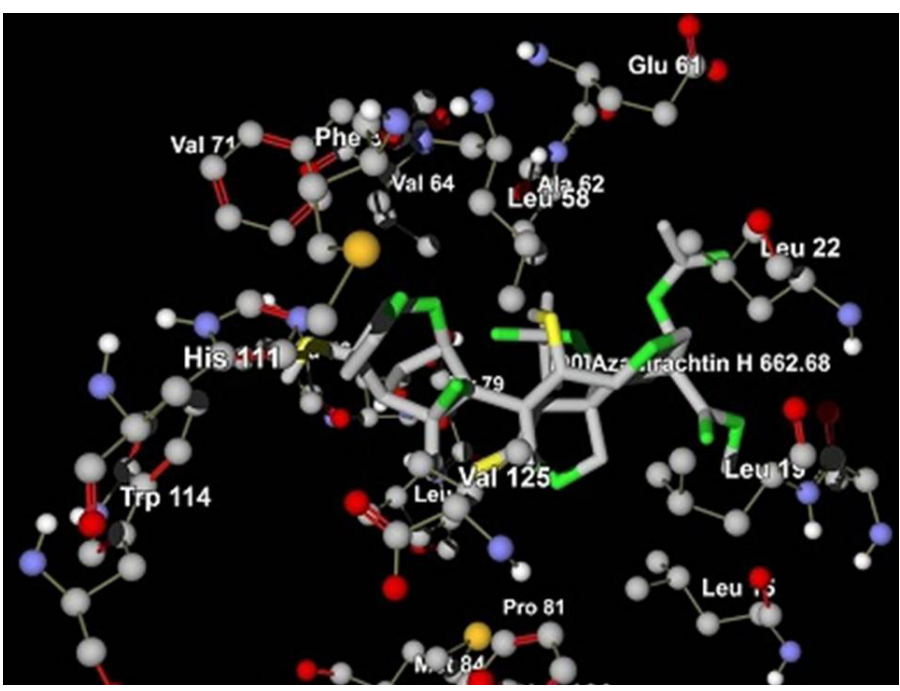

Figure 1: Molecular docking of Azadirachtin H (Standard).

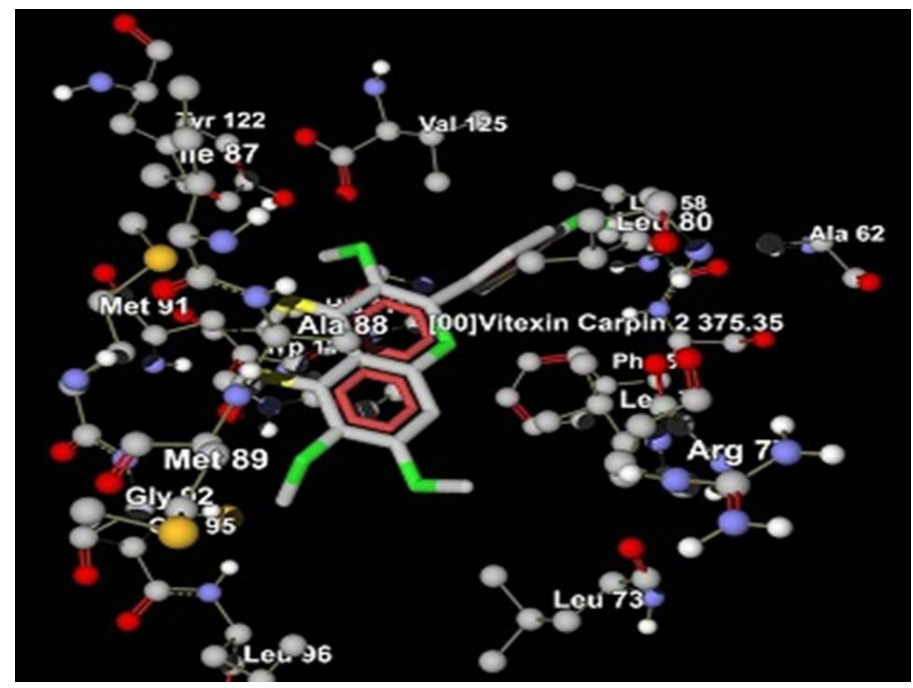

Figure 2: Molecular docking of Vitexicarpin.

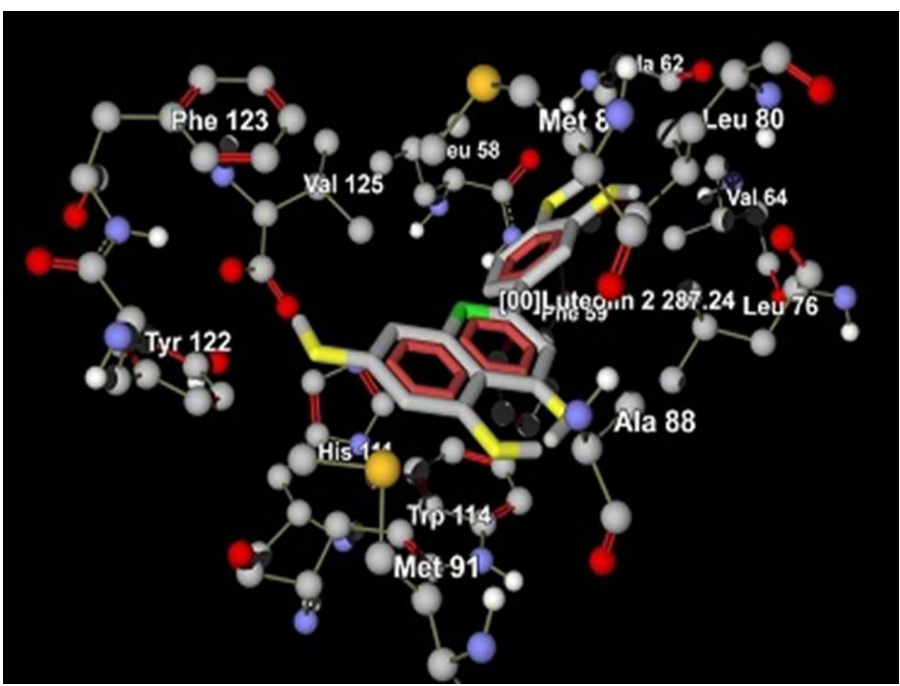

Figure 3: Molecular docking of Luteolin.

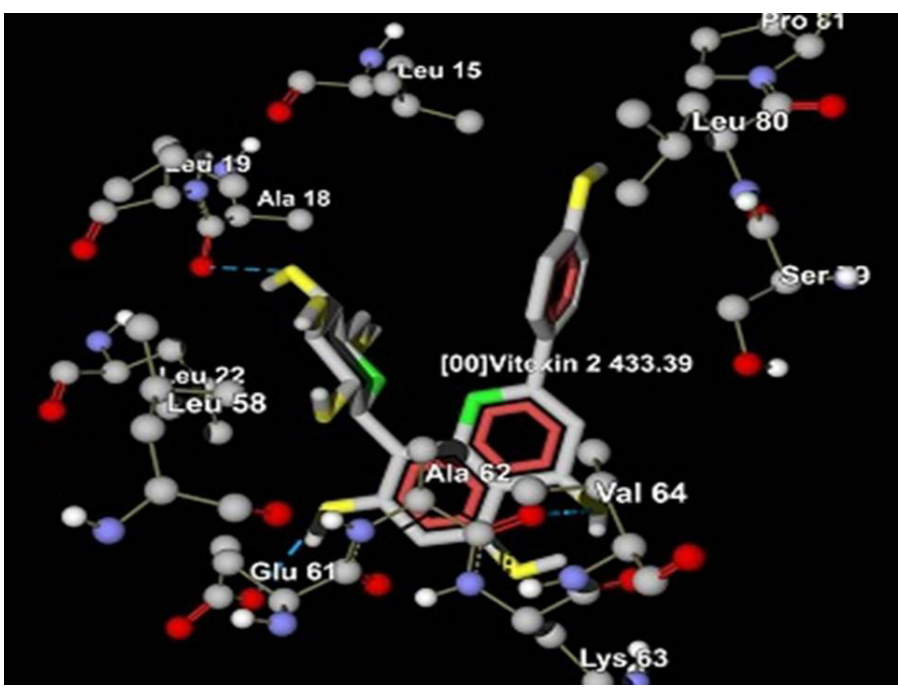

Figure 4: Molecular docking of Vitexin.

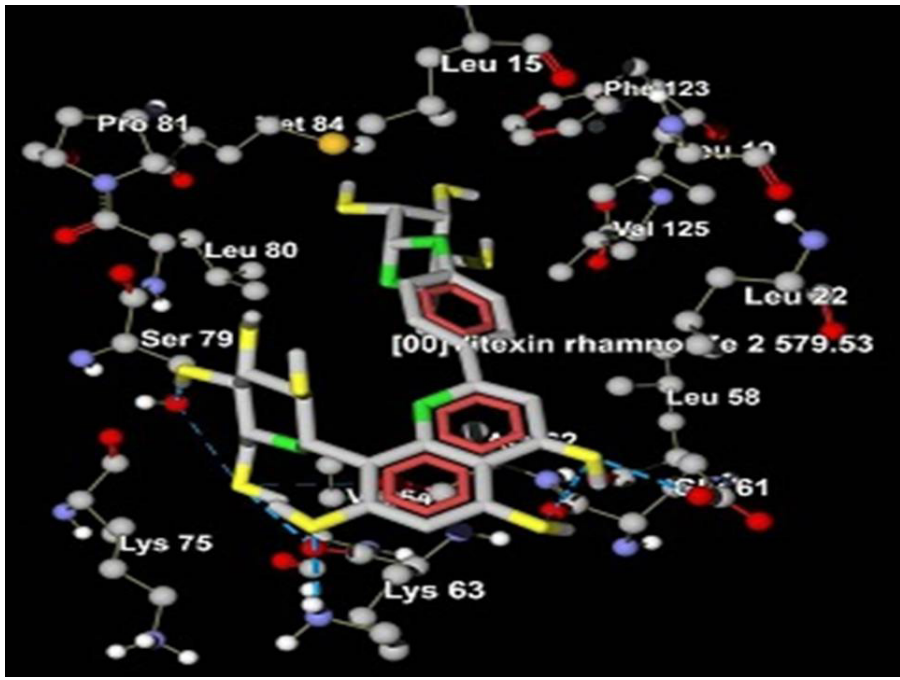

Figure 5: Molecular docking of Vitexin Rhamnoside.

transmitted diseases by mosquitoes and avoidance of mosquito bites remains the first line of safeguard mechanism. The synthetic DEET is considered as a golden standard to compare with other available commercial repellents, which is containing almost all commercial preparation and other synthetic substances lead to produce the resistance. ${ }^{38}$ The larvicidal activity of Vitex negundo Linn extract showed higher mortality rate in Culex quinquefasciatus than compared to other species, which is suggesting that DEET chemical nature of the similar active constituents present in this plant which may induced higher mortality to larvae species. $^{39}$ The natural repellents are an encouraged due to the safety and environmental concerns of synthetic repellents. Natural repellents are showed some impediment, which as an availability of the sources, standardization, commercialization and analysis in order to certify the efficacy and safety of the products. ${ }^{40}$ The different solvent extract of the Vitex negundo showed the larvicidal activity and the results was suggest the plant possess the promising mosquito repellent activity ${ }^{41,42} \mathrm{An}$ in silico molecular docking study was reveal that the plant Vitex negundo possesses on larvicidal effect on different larvae species Culex quinquefasciatus, Aedes aegypti and Aedes albopictus. The complex bonding with 
Sandhya, et al.: Larvicidal Activity and Molecular Docking Studies of Vitexicarpin

least docking score demonstrate that high stability of the compound. The docking results suggested ligand Vitexicarpin formed a stable complex with a least docking score of -87.3733 and compared to standard Azadirachtin $\mathrm{H}$ (-110.77). The active constituent of the Vitex negundo on odorant binding protein was ranked according to their hydrogen bonding, rerank score and MolDock score. The molecular docking score was showed the least docking energy in Vitexicarpin and higher docking energy in Vitexin (-76.2769). This showed interacting residues ALA 88, MET 89, MET 91, VAL 125, GLY 92, LEU 58, LEU 73, LEU 80 of all amino acids contributed to the Vander Waal interactions as compared with standard Azadirachtin $\mathrm{H}$ and it is also had Vander Waal interaction contributing to the stability of the complex. Therefore, the present work, natural products are preferred and it has biodegradable, ecologically safe and have to produce the significant toxicity on target species and more safe and protection for human being.

\section{CONCLUSION}

The present work, larvicidal activity of Vitex negundo Linn against three mosquito species namely Culex quinquefasciatus, Aedes albopictus and Aedes aegypti were screened. The three species larvae were exposed to different concentration of Vitex negundo Linn and $\mathrm{EC}_{50}$ value was calculated. Among three mosquito species Culex quinquefasciatus showed possible results followed by Aedes aegypti and then followed by Aedes albopictus. And further in silico docking study used in Molegro Virtual Docker (MVD) software against Culex quinquefasciatus as it showed better results in in vitro study. An in silico docking studies suggest that most of the phytoconstituents of Vitex negundo Linn possess larvicidal potential as such as standard drug Azadirachtin H. The further in vivo molecular pharmacodynamic and lethal toxicity studies may helpful to get a clear idea about the mechanism of action of active constituents of this plant produce larvicidal effect against species of Culex quinquefasciatus and possible to commercial purpose in near future.

\section{ACKNOWLEDGEMENT}

We sincere thanks to the management of Sri Ramachandra Institute of Higher Education and Research (SRIHER), Porur, Chennai and Dr. Daniel Reegan, Entomologist, Entomology Research Institute, Loyola College, Chennai for providing all necessary facilities to carry out this research work.

\section{REFERENCES}

1. Ralph H. Family Culicidae Meigen, 1818. Mosquito taxonomic inventory [cited Jan 2021]. Available from: http://mosquito-taxonomic-inventory.info/family-culicidae-meigen-18182008.

2. Bouabida H, Djebbar F, Soltani N. Systematic and ecological study of Mosquitoes (Diptera: Culicidae) in the region of Tebessa (Algeria). Entomol faun - Faun Entomol. 2012;65:99-103.

3. Briese DT. Resistance of insect species to microbial pathogens. In: Davidson EW, editor (edt.). Pathogenesis of invertebrate microbial diseases. AllanheldOsmun. Totowa, NJ; 1981. p. 511-45.

4. Davidson EW, Sweeney AW, Cooper R. Comparative field trials of Bacillus sphaericus strain 1593 and $B$. thuringiensis var. israelensis commercial powder formulations. J Econ Entomol. 1981;74(3):350-54. doi: 10.1093/jee/74.3.350.

5. Kirtikar KR, Basu BD. Indian medicinal plants. Indian Plants. 1935;35:1937-40.

6. Nadkarni KM (edt.) [Indian materia medica]. Dr. KM Nadkarni's Indian materia medica: with Ayurvedic, Una ni-Tibbi, Siddha, allopathic, homeopathic, naturopathic $\&$ home remedies, appendices \& indexes. Vol. 1. Popular Prakashan Private Ltd.; 1996. p. 1278-80.

7. The Wealth of India: A dictionary of Indian raw materials and industrial products. N-Pe. 1966;10:522-4

8. Khare CP. Indian medicinal plants: an illustrated dictionary. Vol. 1. New York: Springer-Verlag; 2007. p. 474-76.

9. Warrior PK, Nambiar VPK, Ramankutty C (eds.) (Arya vaidya sala, kottakal). Indian Medicinal Plants: A compendium of 500 species, 1993;1:387-91.

10. Basu NK, Singh GB. A note on the chemical investigation of Vitex negundo L. Indian J Pharmacol. 1944;6:71-4.
11. Joshi V, Merchant JR, Nadkarny VV, Namboori K, Vaghani DD. Chemical components of some Indian medicinal plants. Indian J Chem. 1974;12:226.

12. Misra GS, Subramanian PM. Three new flavones glycosides from Vitex negundo. Planta Med. 1980;38(2):155-60. doi: 10.1055/s-2008-1074853.

13. Singh V, Dayal R, Bartley JP. Volatile constituents of Vitex negundo leaves Planta Med. 1999;65(6):580-82. doi: 10.1055/s-2006-960832, PMID 17260284.

14. Dayal R, Singh V. A comparative study of volatile constituents of Vitex negundo leaves. J Aroma Plant Sci. 2000;22(1B):639-40.

15. Gupta GS, Behari M. Chemical study of the seeds of Vitex negundo L. J Indian Chem Soc. 1973;1:367-8.

16. Díaz F, Chávez D, Lee D, Mi O, Chai HB, Tan GT, Kardono LB, Riswan S Fairchild CR, Wild R, Farnsworth NR, Cordell GA, Pezzuto JM, Kinghorn AD. Cytotoxic flavone analogues of vitexicarpin, a constituent of the leaves of Vitex negundo. J Nat Prod. 2003;66(6):865-7. doi: 10.1021/np0300784, PMID 12828478.

17. Dayal R. Phytochemistry of some useful forest plants. Indian Forester 2004;130(4):456-60

18. Chawla AS, Sharma AK, Handa SS, Dhar KL. Chemical investigation and antiinflammatory activity of Vitex negundo seeds. J Nat Prod. 1992;55(2):163-7. doi: 10.1021/np50080a002, PMID 1624939.

19. Singh P, Mishra G, Srivastava S, Srivastava S, Sangeetha Jha KK et al Phytopharmacological review of Vitex negundo (Sambhalu). Pharmacol Online. $2011 ; 2: 1355-85$

20. Rasaga LY, Morales E, Rideout JA. Antimicrobial compounds from Vitex negundo. Philipp J Sci. 1999;128:21-9.

21. Chandramu C, Manohar RD, Krupadanam DG, Dashavantha RV. Isolation, characterization and biological activity of betulinic acid and ursolic acid from Vitex negundo L. Phytother Res. 2003;17(2):129-34. doi: 10.1002/ptr.1088, PMID 12601674

22. Telang RS, Chatterjee S, Varshneya. Study on analgesic and anti-inflammatory activities of Vitex negundo Linn. Indian J Pharmacol. 1999;31(5):363-6

23. World Health Organization. Guidelines for laboratory and field testing of mosquito larvicides. World Health Organization; 2005 [cited Jan 2021]. Available from: https://apps.who.int/iris/handle/10665/69101.

24. Alouani A, Rehimi N, Soltani N. Larvicidal activity of a neem tree extract (azadirachtin) against mosquito larvae in the Republic of Algeria. Jordan J Biol Sci. 2009;2(1):15-22.

25. McGibbon GA. Interactive biotransformation maps: "ELN" facilitates construction, management, and dissemination of key pathways. Genetic Engineering \& Biotechnology News. 2012;32(10):18-9. doi: 10.1089/gen.32.10.09.

26. Dhivya R, Manimegalai K. In silico molecular docking and molecular dynamics applications in the designing of a new mosquito repellent from the plant Calotropis gigantea targeting the odorant binding protein of Culex quinquefasciatus. Int $\mathrm{J}$ Pharm Phytopharmacol Res. 2013;3(2):134-8.

27. Rathy MC, Sajith U, Harilal CC. Larvicidal efficacy of medicinal plant extracts against the vector mosquito Aedes albopictus. Int J Mosq Res. 2015;2(2):80-2.

28. Raveen R, Kamakshi KT, Deepa M, Arivoli S, Tennyson S. Larvicidal activity of nerium oleander L.(Apocynaceae) flower extracts against Culex quinquefasciatus Say (Diptera: Culicidae). Int J Mosq Res. 2014;1(1):38-42.

29. Deepa M, Palanisamy K, Krishnappa K, Elumalai K. Mosquitocidal activity of Polygala arvensis Willed against Aedes aegypti (Linn.), Anopheles stephensi (Liston.) and Culex quinquefasciatus (Say.)(Diptera: Culicidae). Int J Mosq Res. 2014; 1:30-4

30. Ghosh A, Chowdhury N, Chandra G. Plant extracts as potential mosquito larvicides. Indian J Med Res. 2012;135(5):581-98. PMID 22771587.

31. Rahuman AA, Gopalakrishnan G, Venkatesan P, Geetha K. Larvicidal activity of some Euphorbiaceae plant extracts against Aedes aegypti and Culex quinquefasciatus (Diptera: Culicidae). Parasitol Res. 2008;102(5):867-73. doi: 10.1007/ s00436-007-0839-6, PMID 18163189.

32. Mao Y, Xu X, Xu W, Ishida Y, Leal WS, Ames JB, Clardy J. Crystal and solution structures of an odorant-binding protein from the southern house mosquito complexed with an oviposition pheromone. Proc Natl Acad Sci U S A. 2010; 107(44):19102-7. doi: 10.1073/pnas. 1012274107, PMID 20956299.

33. Bernstein FC, Koetzle TF, Williams GJB, Meyer EF Jr, Brice MD, Rodgers JR, Kennard O, Shimanouchi T, Tasumi M. The Protein Data Bank: A computer-based archival file for macromolecular structures. J Mol Biol. 1977;112(3):535-42. doi: 10.1016/s0022-2836(77)80200-3, PMID 875032

34. Thomsen R, Christensen MH. MolDock: a new technique for high-accuracy molecular docking. J Med Chem. 2006;49(11):3315-21. doi: 10.1021/jm051197e, PMID 16722650

35. Gehlhaar DK, Verkhivker G, Rejto P, Fogel D, Fogel L, Freer S. Docking conformationally flexible small molecules into a protein binding site through evolutionary programming. In: Donnell JM, Reynolds R, Fogel D, editors. Proceedings of the fourth international conference on evolutionary programming; 1995. p. 615-27.

36. Yang JM, Chen CC. GEMDOCK: a generic evolutionary method for molecular docking. Proteins. 2004;55(2):288-304. doi: 10.1002/prot.20035, PMID 15048822.

37. Klun JA, Strickman D, Rowton E, Williams J, Kramer M, Roberts D, Debboun M Comparative resistance of Anopheles albimanus and Aedes aegypti to N,N- 
diethyl-3-methylbenzamide (Deet) and 2-methylpiperidinyl-3-cyclohexen1-carboxamide (Al3-37220) in laboratory human-volunteer repellent assays. J Med Entomol. 2004;41(3):418-22. doi: 10.1603/0022-2585-41.3.418, PMID 15185944.

38. Rahuman AA, Gopalakrishnan G, Venkatesan P, Geetha K. Larvicidal activity of some Euphorbiaceae plant extracts against Aedes aegypti and Culex quinquefasciatus (Diptera: Culicidae). Parasitol Res. 2008;102(5):867-73. doi: 10.1007/ s00436-007-0839-6, PMID 18163189.

39. Khater HF. Prospects of botanical biopesticides in insect pest management.
Pharmacologia. 2012;3(12):641-56. doi: 10.5567/pharmacologia.2012.641.656.

40. Kamaraj C, Bagavan A, Rahuman AA, Zahir AA, Elango G, Pandiyan G. Larvicidal potential of medicinal plant extracts against Anopheles subpictus Grassi and Culex tritaeniorhynchus Giles (Diptera: Culicidae). Parasitol Res. 2009;104(5):1163-71. doi: 10.1007/s00436-008-1306-8, PMID 19085005.

41. Kamaraj C, Bagavan A, Elango G, Zahir AA, Rajakumar G, Marimuthu S, Santhoshkumar T, Rahuman AA. Larvicidal activity of medicinal plant extracts against Anopheles subpictus \& Culex tritaeniorhynchus. Indian J Med Res. 2011;134:101-6. PMID 21808141.

Article History: Received: 03-04-21;Revised: 25-04-21;Accepted: 03-06-21

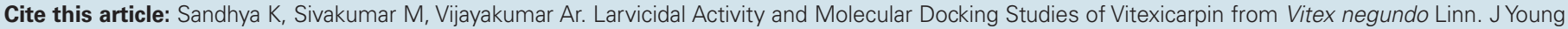
Pharm. 2021;13(3):223-8. 